\title{
TRACE INEQUALITIES FOR POSITIVE SEMIDEFINITE MATRICES
}

\author{
Projesh Nath Choudhury \\ AND \\ K.C. SivakumaR \\ Department of Mathematics \\ Indian Institute of Technology Madras \\ Chennai 600 036, India \\ e-mail: n.projesh@gmail.com \\ kcskumar@iitm.ac.in
}

\begin{abstract}
Certain trace inequalities for positive definite matrices are generalized for positive semidefinite matrices using the notion of the group generalized inverse.
\end{abstract}

Keywords: positive semidefinite matrix, group inverse, trace inequalities.

2010 Mathematics Subject Classification: 15B57, 15A09, 15 A39.

\section{REFERENCES}

[1] K.M. Abadir and J.R. Magnus, Matrix Algebra (Cambridge University Press, New York, USA, 2005).

[2] E.V. Belmega, M. Jungers and S. Lasaulce, A generalization of a trace inequality for positive definite matrices, Aust. J. Math. Anal. Appl. 7 (2010) no. 2 Art. 26, 5 pp.

[3] E.V. Belmega, S. Lasaulce and M. Debbah, A trace inequality for positive definite matrices, J. Inequal. Pure Appl. Math. 10 (2009) no. 1 Art. 5, 4 pp.

[4] A. Ben-Israel and T.N.E. Greville, Generalized Inverses: Theory and Applications (Springer-Verlag, New York, 2003). doi: $10.1007 / \mathrm{b} 97366$

[5] S. Furuichi and M. Lin, Refinements of the trace inequality of Belmega, Lasaulce and Debbah, Aust. J. Math. Anal. Appl. 7 (2010) no. 2 Art. 23, 4 pp. 
[6] J.B. Lasserre, A trace inequality for matrix product, IEEE Trans. Automat. Control 40 (1995) 1500-1501. doi:10.1109/9.402252

[7] C.K. Li and R. Mathias, Inequalities on singular values of block triangular matrices, SIAM J. Matrix Anal. Appl. 24 (2002) 126-131. doi:10.1137/S0895479801398517

[8] E. Telatar, Capacity of multi-antenna Gaussian channels, Eur. Trans. on Telecomm. 10 (1999) 585-595. doi:10.1002/ett.4460100604

[9] Z. Ulukök and R. Türkmen, On some matrix trace inequalities, J. Inequal. Appl. 2010 (Art.ID 201486) 8 pp. doi: $10.1155 / 2010 / 201486$

[10] H.J. Werner, On the matrix monotonicity of generalized inversion, Lin. Alg. Appl. 27 (1979) 141-145. doi:10.1016/0024-3795(79)90036-3

[11] Z.P. Yang and X.X Feng, A note on the trace inequality for products of Hermitian matrix power, J. Inequal. Pure Appl. Math. 3 (2002) no. 5 Article 78, 12 pp.

[12] F. Zhang, The Schur Complement and Its Applications (Springer, New York, 2005). doi:10.1007/b105056

[13] F. Zhang, Matrix Theory: Basic Results and Techniques (Springer, New York, 2011). doi:10.1007/978-1-4614-1099-7

Received 18 December 2016 Revised 8 February 2017 